\title{
Uma avaliação sobre a eficácia do método CSF no diagnóstico de helmintíases intestinais
}

\author{
An evaluation of the efficacy of the CSF method \\ for diagnosing intestinal helminthiases \\ Ruth Semira Rodriguez Alarcón' ${ }^{1}$, Vicente Amato Neto', \\ Erika Gakiya $^{1}$ e Rita Cristina Bezerra ${ }^{1}$
}

\section{RESUMO}

O método CSF, recentemente proposto para diagnóstico de helmintíases intestinais foi comparado com outros (direto; Faust e cols; sedimentação espontânea em água; Kato-Katz) habitualmente usados com essa finalidade. Houve desempenho satisfatório, revelando que tal técnica pode ser adotada em tarefas para diagnóstico ou análise epidemiológicas.

Palavras-chaves: Helmintíases intestinais. Método CSF. Avaliação.

\begin{abstract}
The recently proposed CSF method for diagnosing intestinal helminthiases was compared with the other methods (direct; Faust et al.; spontaneous sedimentation in water; and Kato-Katz) that are routinely for this purpose. The CSF method performed satisfactorily, thus showing that this technique can be adopted for use in diagnoses or epidemiological analyses.
\end{abstract}

Key-words: Intestinal helminthiases. CSF method. Evaluation.

Durante muito tempo vem sendo utilizado no Brasil método denominado Kato-Katz para diagnóstico de helmintíases intestinais. Esse processo permite também determinações quantitativas e particularmente ganhou prestígio sobretudo quanto à evidenciação de ovos de Schistosoma mansoni em atividades médico-assistenciais ou avaliações epidemiológicas. Depois de intensa aceitação, inclusive por órgãos governamentais, deixou de ser comercializado, convindo salientar que a forma de disponibilidade, sob a forma de "kits", facilitava fundamentalmente o uso.

Diante da circunstância mencionada Ferreira ${ }^{3}$ considerou conveniente idealizar técnica sucedânea, alternativa, inclusive valorizando conhecimentos prévios ${ }^{2} 56$. Assim, estipulou proposição que se mostrou eficaz. Os fundamentos desse procedimento estão a seguir relatados.

Os esfregaços espessos de fezes humanas podem afigurar-se adequados para a identificação de ovos e larvas de helmintos por meio da busca de homogeneidade de índices de refração. Embora seja possível obter esse efeito através de simples espalhamento de um fragmento de fezes sobre uma lâmina de microscopia, solução de glicerol tem sido usada rotineiramente para tal fim. Visando à praticabilidade, elaborou-se uma técnica quantitativa em que é utilizada solução de sacarose (índice de refração = 1,49) para reduzir o efeito da difusão da luz produzido pelo material particulado. 0 volume da amostra fecal a examinar em uma lâmina corresponde ao da capacidade cilíndrica da placa medidora $\left(38,5 \mathrm{~mm}^{3}\right)$. Avaliações de sensibilidade e contagem de ovos tornam-se, portanto, de fácil execução.

É oportuno e conveniente agregar informações a propósito da utilidade desse processo. Para tanto, examinamos fezes de 272 alunos, com idades de seis a doze anos de idade, de escola da periferia de São Paulo empregando cinco tipos de métodos: direto, Faust e cols, sedimentação espontânea em água, CSF$^{3}$ e Kato-Katz ${ }^{4}$. As maneiras para realizá-los figuram nas referências correspondentes e a respeito dos três primeiros no compêndio de autoria de Amato Neto e Corrêa ${ }^{1}$. Anotamos os resultados na Tabela 1.

\footnotetext{
1. Laboratório de Investigação Médica, Parasitologia do Hospital das Clínicas da Faculdade de Medicina da Universidade de São Paulo, São Paulo, SP.

Endereço para correspondência: Prof. Vicente Amato Neto. Laboratório de Investigação Médica - Parasitologia/HC/FM/USP. Av. Dr. Enéas de Carvalho Aguiar 470, 05403-000 São Paulo, SP

Telefax: $55113066-7042$

e-mail: amatonet@usp.br

recebido para publicação em 27/7/2006

Aceito em 27/4/2007
} 
Tabela 1 - Diagnóstico de helmintíases intestinais em 272 exames de fezes: comparação entre cinco métodos (números positivos e porcentagens).

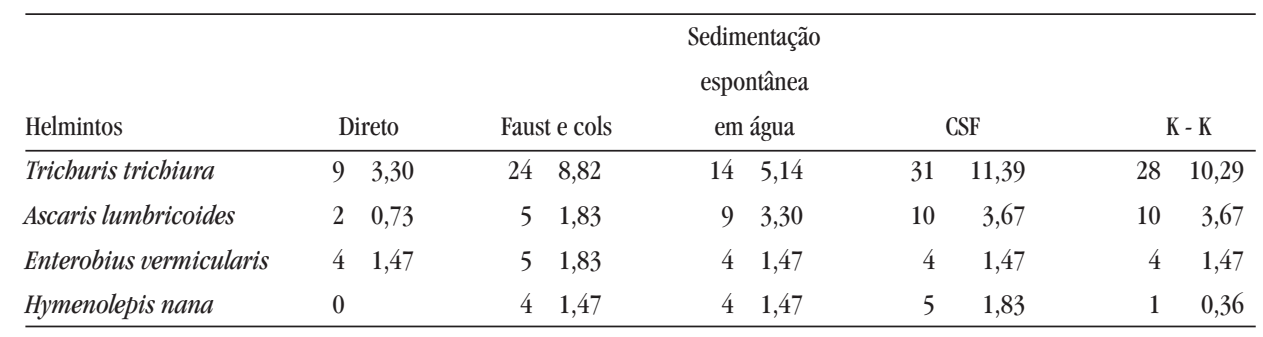

CSF: Cláudio Santos Ferreira: K-K: Kato-Katz.

As verificações apontadas mostram expressiva heterogeneidade quanto aos números de positivos, revelando claras diversidades de sensibilidades entre os métodos. As taxas concernentes ao Enterobius vermicularis não são valorizáveis, pois as técnicas afiguram-se, reconhecidamente, pouco eficazes para reconhecimento dessa verminose.

Diante das cifras apuradas impõe-se um comentário. Elas, muitas vezes discretas, aparecem em níveis inferiores aos registrados há algum tempo atrás. Em certos lugares enteroparasitoses ficaram felizmente menos freqüentes e o que se passa com a ancilostomíase é exemplo disso. Melhorias de caráter sanitário, pelo menos parciais, cooperam bastante a respeito. Os escolares que compõem a presente casuística residem em área na qual a prevenção de doenças não é a ideal, mas que já mostra determinados benefícios higiênicos e ambientais.

Como fato fundamental, nesta apreciação, percebemos que a técnica CSF não se comportou, ao ser cogitado o diagnóstico de helmintíases intestinais, com inferioridade perante os outros processos com os quais foi comparada e são utilizados habitualmente para cumprir tal objetivo. Pelo contrário, evidenciou alguma superioridade, podendo merecer confiabilidade quando desejado apoio para diagnóstico ou cumprimento de análises epidemiológicas.

\section{REFERÊNCIAS}

1. Amato Neto V, Corrêa LL. Exame parasitológico de fezes. Editora Sarvier, São Paulo, 1991.

2. Ferreira CS, Carvalho ME. Diafanização de esfregaços de fezes. Revista de Saúde Pública 6:19-23,1972.

3. Ferreira C S. Refractive index matching applied to fecal smear clearing. Revista do Instituto de Medicina Tropical de São Paulo 47:347-350, 2005.

4. Katz N, Chaves A, Pellegrino J. A simple device for quantitative stool thick technique in schistosomiasis mansoni. Revista do Instituto de Medicina Tropical de São Paulo 14:397-400, 1972.

5. Komiya Y, Kobayashi A. Evaluation of Kato's thick smear technic with a celloplane cover for helminth eggs in feces. Japanese Jounal of Medical Science and Biology 19:59-64,1966.

6. Teles HMS, Ferreira CS, Carvalho ME, Zacharias F, Magalhães LA. Eficiência do diagnóstico coproscópico de Schistosoma mansoni em fezes prensadas. Revista da Sociedade Brasileira de Medicina Tropical 36:503-507,2003 